\title{
Investigation of Pharmacological Activity of Caralluma penicillata: Anti-Inflammatory Properties and Gastritis Protection against Indomethacin in Adult Guinea Pigs
}

\author{
Nabil Albaser, ${ }^{1,2}$ Najeeb Ghanem, ${ }^{1,2}$ Mohanad Shehab, ${ }^{1}$ \\ Adnan Al-Adhal, ${ }^{1,2}$ and Mohammed Amood AL-Kamarany ${ }^{2,3}$ \\ ${ }^{1}$ Department of Pharmacology and Therapeutic, Faculty of Medicine and Health Sciences, Sana'a University, Sana'a, Yemen \\ ${ }^{2}$ Tihama Foundation for Drug Studies and Research, Hodeidah, Yemen \\ ${ }^{3}$ Department of Pharmacy Practice, Faculty of Clinical Pharmacy, Hodeidah University, P.O. Box 3114, Hodeidah, Yemen
}

Correspondence should be addressed to Mohammed Amood AL-Kamarany; alkamarany@yahoo.com

Received 17 July 2014; Accepted 15 October 2014; Published 4 December 2014

Academic Editor: Carmela Saturnino

Copyright (C) 2014 Nabil Albaser et al. This is an open access article distributed under the Creative Commons Attribution License, which permits unrestricted use, distribution, and reproduction in any medium, provided the original work is properly cited.

Caralluma is a plant that possessing a great therapeutic potential in folk medicine in Yemen, namely, Caralluma penicillata (C. penicillata) as antiulcer. The study aims to evaluate the anti-inflammatory properties and gastritis protection activity of $C$. penicillata against indomethacin in adult guinea pigs. The study was divided into four parts: firstly, the optimum dose of extract as anti-inflammatory effect was determined. Secondly, the acute anti-inflammatory effect of extract were estimated. Thirdly, the repeated doses of extract against chronic inflammation was estimated. The anti-inflammatory activity of extract was compared with indomethacin as a prototype of drug against inflammation. Fourthly, the gastritis protection properties of extract with/without indomethacin were performed. The results showed that a $400 \mathrm{mg} / \mathrm{kg}$ of $10 \%$ ethanol extract produced the maximum of antiinflammatory effect. Also, the single dose of extract was equipotent for indomethacin $(10 \mathrm{mg} / \mathrm{kg})$, but shorter in duration with regard to acute anti-inflammatory effect. In addition, the repeated doses of extract against chronic inflammation were less potent than indomethacin with regard to ulcerogenic effect. On the other hand, extract-indomethacin combination reduced the gastritis effect of indomethacin based on ulcer index and histological study.

\section{Introduction}

The genus Caralluma (C.) belongs to the family Asclepiadaceae (also known as the milk weed family) which comprises some 200 genera and 2500 species [1]. It is a plant species possessing a great therapeutic potential in folk medicine. The medicinal properties of $C$. species include antihyperglycemic activity of $C$. attenuata [2], while $C$. tuberculata also offered protection against mucosal damage of stomach [3]. Plants belonging to this genus are rich in esteried polyhydroxypregnane glycosides, some of which showed antitumor activity and others were postulated as precursors of cardenolides $[4,5]$. C. arabica and C. umbellate have shown antinociceptive and anti-inflammatory properties $[6,7]$. The use of $C$. species in traditional medicinal was recorded in many studies and C. penicillata has been used in Yemeni traditional medicine for the treatment of peptic ulcer and as being antihyperglycemic. Also, some populations used it for the treatment of snake and scorpion bites [8]. The plant, particularly, C. negevensis, is also used by Bedouins to treat chronic lung diseases, such as tuberculosis and cancer [1]. However, the stem juice of C. umbellate warmed and mixed with turmeric powder is given in stomach disorders and abdominal pain [9]. Also C. arabica is commonly used in folk medicine as decoction as being antipyretic and antirheumatic [6].

Several active substances were isolated from various members of $C$. species such as pregnane glycosides and flavonoids. Pregnane glycosides are named Carambelloside I and II, which were isolated, particularly, from C. umbellate 
[10] and another twenty new pregnane glycosides were isolated from the whole plant of Caralluma negevensis [11]. Megastigmane glycosides and flavonol were isolated from $C$. retrospiciens [1]. However, one of these flavone glycosides is named luteolin-4-O-neohesperidoside which was isolated from another species [2]. Pregnane ester glycosides named caretroside A and biocide were isolated from C. retrospiciens [12]. Oxypregnane glycosides are named penicillosides A$\mathrm{G}$, which were isolated from $C$. penicillata $[13,14]$. The most common $C$. species in Yemen is $C$. penicillata that widely is used in folk medicine having an antiulcer effect. C. penicillata has been used in Yemeni traditional medicine for the treatment of peptic ulcer and as anti-inflammatory. No scientifically based study was performed on effects of this plant. Therefore this study aimed to evaluate the pharmacological activity of $C$. penicillata, namely, anti-inflammatory properties and gastritis protection against indomethacin in male adult guinea pigs.

\section{Material and Methods}

2.1. Standards, Reagents, and Plant Materials. Indomethacin was obtained from MSD (UK) in powder form (secondary standard). Diazepam of Hoffman La Rhoche (Switzerland) in injectable form was purchased. Polysorbate 80 USP was purchased (Sigma Chemical Co. Germany). Ethanol of Merck, Darmstadt (Germany), was purchased. Fresh egg albumin was prepared before use.

2.2. Extraction Assay. The aerial parts of the C. penicillata, weighing $5 \mathrm{~kg}$, were chopped and crushed in mixer and extracted with $10 \%$ ethanol at room temperature. The extract was dried by using freeze dryer.

2.3. Animal Handling. Adult male guineas pigs with uniform locally bread strain that weighing from $350 \mathrm{~g}$ to $405 \mathrm{~g}$ were used throughout this study. They were chosen since they proved most to be convenient for the purpose of the study besides their availability, ease of handling, and cheapness. The choice of male guinea pig was undertaken to avoid interaction with female sex hormones and in order to eliminate the influence of estrous cycle and pregnancy in female guinea pig on tested parameters. Before starting work, the animals were left for one week to acclimatize. They were kept at constant temperature and allowed for food and water ad libitum. They were fed on grass and carrots.

2.4. Study Design. This pilot study was conducted in four parts to determine the anti-inflammatory activity of $C$. penicillata selected from Yemen where it remains the most frequently used traditional therapeutic to treat peptic ulcer. The first part was devoted to determining the antiinflammatory dose of extract. The second part, the acute antiinflammatory effect of extract, was performed and compared with indomethacin as a prototype of drug against inflammation. The third part, the repeated doses of extract, was estimated against chronic inflammatory and compared with indomethacin; the fourth part, the gastritis protection activity of extract against indomethacin, was estimated.

2.5. Extract and Indomethacin Preparations. The dried extract $(85 \mathrm{~g})$ was resuspended with distilled water for pharmacological studies. The doses of C. penicillata extract were determined according to the pilot study. In this work, indomethacin was dissolved in 5\% Polysorbate 80 $(10 \mathrm{mg} / \mathrm{mL})$. It was freshly prepared before being used every day [15].

\subsection{Induction of Inflammation}

2.6.1. Induction of Acute Inflammation. Hind paw oedema inflammation in adult male guinea pigs was conducted using a modification of the method described [16]. As described by Akah and Nwambie 1994 [17], $0.5 \mathrm{~mL} / \mathrm{kg}$ of fresh egg albumin was injected subcutaneously into the right hind paw of each guinea pig under the subplantar aponeurosis. The paw volume was measured at half an hour after the injection using a plethysmograph by dipping the foot in the mercury bath of the plethysmograph apparatus up to the anatomical hairline on lateral malleolus. The inhibitory activity was calculated according to the following formula [18]:

$$
\begin{aligned}
\text { Anti-inflammation activity } & =(\% \text { Inhibition }) \\
& =\left(1-\frac{D}{C}\right) \times 100,
\end{aligned}
$$

where $D$ represents the percentage difference in paw volume after injection of the extract and $C$ represents the percentage difference of volume in the control group. On the other hand, for the animals to be handled easily, all received diazepam $(2.5 \mathrm{mg} / \mathrm{kg})$ intraperitoneally 30 minutes before inducing edema as a moderate sedative [19].

2.6.2. Induction of Chronic Inflammation. Chronic inflammation was induced by cotton pellet implantation [20], this protocol was described by Sheth et al., 1972 [21] with slight modification to be used for adult male guinea pigs. The animals were fasted 12 hours prior to implantation. Sterile pellets of pure cotton of average weight $(50 \mathrm{mg} \pm 1)$ were used in this experiment. They were sterilized by heat before implantation. The groin region of all animals was shaved and sterilized by alcohol. A median $2.5 \mathrm{~cm}$ subcutaneous incision was performed in groin of each animal under light ether anesthesia. Two of previous prepared cotton pellets were subcutaneously implanted on each side of midline through the incision. It was then sutured by silk threads. The sutured incisions were frequently sterilized by alcohol. After 8 days of cotton pellet implantation, all animals were sacrificed and the cotton pellets were extracted, dried at $70^{\circ} \mathrm{C}$, and weighted. The increase in weight of cotton pellet was considered an indicator of chronic inflammation. 


\subsection{Anti-Inflammatory Assay of C. penicillata}

2.7.1. Determination of Optimum Dose of C. penicillata Extract. It was devoted to evaluating the anti-inflammatory effect of C. penicillata and to find out the effective dose of $10 \%$ ethanol extract for further use in experimental studies. As an initial pilot experiment, increasing doses of C. penicillata (200, 400, and $600 \mathrm{mg} / \mathrm{kg}$ ) were administered intragastrically and studied in the presence of fresh egg albumin-induced hind paw oedema in male adult guinea pigs. Twenty-four guinea pigs were used in this experiment, they were divided into 4 groups, and each group consisted of six animals. The first group served as control and they received oral single 5\% Polysorbate 80 in comparable amount to tested drug and plant extract one hour before induction of egg albumin for acute inflammation. Respectively, the second, third, and fourth groups served to study the effect of $200 \mathrm{mg} / \mathrm{kg}, 400 \mathrm{mg} / \mathrm{kg}$, and $600 \mathrm{mg} / \mathrm{kg}$ of $10 \%$ ethanol extract of $C$. penicillata on fresh egg albumin induced paw oedema and the plant extract was administered by intragastric tube. The volume of paw oedema in each group was determined with plethysmograph apparatus and the subsequent readings were taken at an interval of $30 \mathrm{~min}$ for a total of $180 \mathrm{~min}$. The minimal dose that produced maximal activity effect was found and used throughout the second part of experiment.

2.7.2. Effect Determination of C. penicillata Extract on Acute Inflammation Model. It was devoted to investigating the effect of acute intragastric administration of $C$. penicillata on fresh egg albumin induced hind paw oedema in guinea pigs by injecting $0.5 \mathrm{~mL} / \mathrm{kg}$ of fresh egg albumin into the subplantar surface of the right hind paw. Eighteen adult male guinea pigs were used in this experiment. They were divided into 3 groups each consisting of 6 animals. The first group served as control and they received single 5\% Polysorbate 80 intragastrically in comparable volumes to drugs used. The second group served to study the effect of C. penicillata extract and they were given oral single extract of C. penicillata in a dose of $400 \mathrm{mg} / \mathrm{kg}$. The third group served to study the effect of indomethacin and they received oral single indomethacin in a dose of $10 \mathrm{mg} / \mathrm{kg}$. Guinea pig hind paw oedema was induced by subplantar injection of fresh egg albumin $(0.5 \mathrm{~mL} / \mathrm{kg})$, using a syringe of $1 \mathrm{~mL}$. Acute inflammation of the hind paw was induced in each of the guinea pigs by injecting $0.5 \mathrm{~mL} / \mathrm{kg}$ of fresh egg albumin into the subplantar surface of the right hind paw $1 \mathrm{hr}$ after drugs administration. Volume of the hind paw was assessed during the period of $3 \mathrm{hr}$ at $30 \mathrm{~min}$ interval after the injection of the inflammatory agent. Increase in the volume of right hind paws was taken as an indication of paw oedema. Oedema was assessed in terms of the difference in original volume of the right hind paw before the injection of inflammatory agent and its volume at time $(30,60,90,120,150$, and $180 \mathrm{~min})$ following fresh egg albumin administration. The increase in the right hind paw (induced by the injection of fresh egg albumin) was compared with the original volume of the right hind paw before oedema induction.
2.7.3. Effect Determination of C. penicillata Extract on Chronic Inflammation Model. It was devoted to investigating the effect of $C$. penicillata on cotton pellet induced granuloma [22]. A model of chronic inflammation was carried out by implantation of sterile cotton pellets $(50 \pm 1 \mathrm{mg})$ in guinea pig paw. Thirty guinea pigs were used in this experiment. They were divided into 5 groups each consisting of 6 animals. The first group served as control and the animals received 5\% Polysorbate 80 single intragastrically in comparable volumes to drugs used for 7 consecutive days from the day of cotton pellet implantation. The second group served to study the effect of $C$. penicillata; the animals were given oral dose of C. penicillata $(400 \mathrm{mg} / \mathrm{kg})$ once daily at $8 \mathrm{PM}$ for 7 consecutive days from the day of cotton pellet implantation. The third group served to study the effect of indomethacin as a test reference and the animals were given oral dose of indomethacin $(10 \mathrm{mg} / \mathrm{kg})$ once daily as aqueous suspensions using $5 \%$ Polysorbate 80 by [23] at 8 PM for 7 consecutive days from the day of cotton pellet implantation. The fourth group served to study the effect of combination dose of $C$. penicillata and indomethacin and the animals were given oral dose of indomethacin $(5 \mathrm{mg} / \mathrm{kg})$ and C. penicillata $(200 \mathrm{mg} / \mathrm{kg})$ once daily at $8 \mathrm{PM}$ for 7 consecutive days from the day of cotton pellet implantation. The fifth group served to study the effect of combination dose of C. penicillata and indomethacin and the animals were given oral dose of indomethacin $(10 \mathrm{mg} / \mathrm{kg})$ and C. penicillata $(400 \mathrm{mg} / \mathrm{kg})$ once daily at 8 PM for 7 consecutive days from the day of cotton pellet implantation. The combination doses of C. penicillata and dose of indomethacin were administered to animals groups separately with 30 minutes between them.

The same volume of distilled water was applied to the control group. After $30 \mathrm{~min}$, a model of chronic inflammation was induced in all animals; the animals were anesthetized with light ether. Under sterile conditions, cotton pellets, weighing (50 mg \pm 1 ) each, were implanted an interscapular distance under the skin, according to the method of Swingle and Shideman, 1972 [24]. After 7 days of drugs administration all animals were sacrificed by decapitation.

2.8. Antiulcerogenic Assay of C. penicillata. They were dissected for stomach and cotton pellets. Cotton pellets were removed, dried, and weighed. The stomachs were cut open along the greater curvature rinsed with normal saline for the scoring of ulcer index. In addition, they were kept in $10 \%$ formalin before histological examinations were performed. The stomach tissues were subjected to normal routine histological procedures, stained with hematoxylin-eosin and examined using the light microscopy for any morphological changes [25-27].

2.9. Data Analysis. Data obtained were analysed by using descriptive analysis, namely, mean and standard error (SE). Also, Student's $t$-test was used to explore the anti-inflammatory and antiulcerogenic properties of C. penicillata and for comparison with indomethacin. 


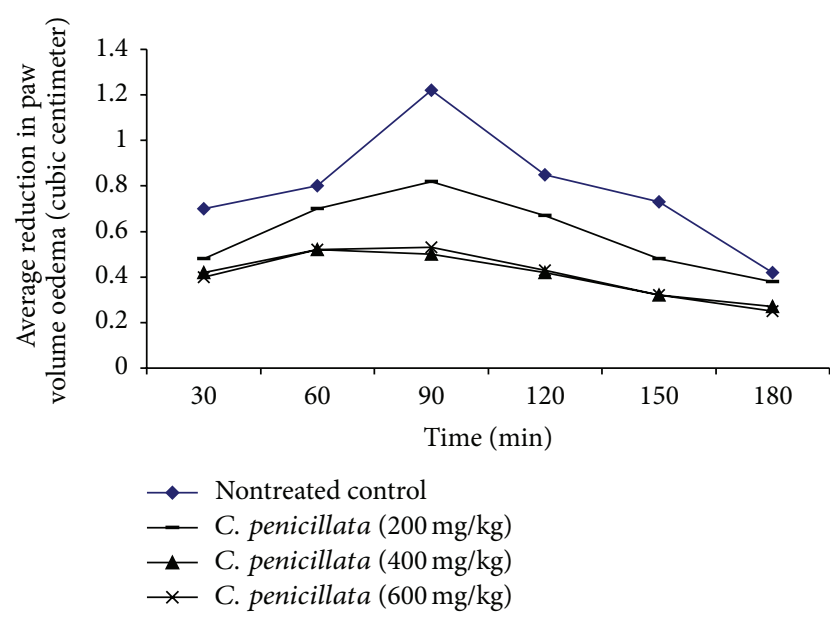

FIGURE 1: The maximum anti-inflammatory effect of different intragastric doses of $10 \%$ ethanol extract of $C$. penicillata admitted singly on average $(\mathrm{M} \pm \mathrm{SE})$ paw volume oedema (cubic centimeter) of fresh egg albumin $(0.5 \mathrm{~mL} / \mathrm{kg})$ induced paw oedema in adult male guinea pigs $(n=6)$ after 30, 60, 90, 120, 150, and 180 minutes and compared with nontreated control group.

\section{Results}

3.1. Anti-Inflammatory Dose of C. penicillata Extract. The Anti-inflammatory effect of single intragastric administration of different doses of C. penicillata on fresh egg albumen induced paw oedema in adult male guinea pigs to find out the effective dose for further use in experimental studies. The normal volume of hind paw of adult male guinea pig was $3.15 \pm 0.10 \mathrm{cc}$. Induction of acute inflammation by injecting fresh egg albumin $(0.5 \mathrm{~mL} / \mathrm{kg})$ into subplantar aponeurosis of the right hind paw increased its volume with the time (Table 1). A dose of $200 \mathrm{mg} / \mathrm{kg}$ of $10 \%$ ethanol extract of C. penicillata significantly reduced $(P<0.05)$ the average volume of egg albumen induced oedema with the time compared with the original paw volume and nontreated control group except at $180 \mathrm{~min}$ for nontreated control group in which no statistically significant difference was observed $(P>0.05)$. This may imply partial improvement of acute egg albumen induced oedema after the administration of this extract dose. The dose of $400 \mathrm{mg} / \mathrm{kg}$ of extract was more effective than the previous dose $(200 \mathrm{mg} / \mathrm{kg})$. It significantly reduced the volume of paw oedema more than $200 \mathrm{mg} / \mathrm{kg}$ with the time compared with the original paw volume $(P<$ 0.05) and nontreated control group. The administration of $600 \mathrm{mg} / \mathrm{kg}$ of extract significantly reduced $(P<0.05)$ the volume of paw oedema with the time compared with the original volume and nontreated control group. Also final dose had the same effect of $400 \mathrm{mg} / \mathrm{kg}$. Economically, this means that the most effective dose of extract was $400 \mathrm{mg} / \mathrm{kg}$ (Figure 1).

3.2. Effect of C. penicillata on Acute Inflammation Model. The results of anti-inflammatory activity of $C$. penicillata were summarized in Table 2. The intragastric administration of single dose of $C$. penicillata $(400 \mathrm{mg} / \mathrm{kg}$ ) significantly reduced $(P<0.05)$ the average volume of paw oedema by $59 \%, 51 \%$,
$56 \%$, and $36 \%$ after $90,120,150$, and 180 minutes, respectively, compared with the original volume of paw. Also, the intragastric administration of indomethacin $(10 \mathrm{mg} / \mathrm{kg})$ significantly reduced $(P<0.05)$ the average volume of the paw oedema by $61 \%, 65 \%, 77 \%$, and $71 \%$ after $90,120,150$, and 180 minutes, respectively, compared with the original volume of paw. On the other hand, statistically significant difference $(P<0.05)$ was observed between nontreated control group and tested and indomethacin group. In addition, C. penicillata had $40 \%, 88 \%$, and $125 \%$ less than anti-inflammatory effect of indomethacin after 120,150, and 180 minutes, respectively; on the other hand, significant difference $(P<0.05)$ was observed between both groups at the same time (Table 2).

\subsection{Effect of C. penicillata on Chronic Inflammation Model.} Table 3 showed the anti-inflammatory effect of repeated intragastric administration of C. penicillata $(400 \mathrm{mg} / \mathrm{kg})$ and indomethacin $(10 \mathrm{mg} / \mathrm{kg})$ on cotton pellet induced granuloma as a model of chronic inflammation; significant difference results $(P<0.05)$ between both groups were summarized in this table. On the other hand, implantation of $50 \mathrm{mg} \pm 1$ cotton pellet in male adult guinea pig caused in the formation of the granulomatous chronic inflammation weighed $83.9 \pm 3.2 \mathrm{mg}$. The indomethacin $10 \mathrm{mg} / \mathrm{kg}$ and C. penicillata $400 \mathrm{mg} / \mathrm{kg}$ produced significant antiinflammatory effect $(P<0.05)$ that was evident in the reduction of the weight of cotton pellet induced granuloma by $74 \%$ and $64 \%$, respectively, compared with nontreated control group. Also, the combination of the above mentioned agents in half doses reduced the weight of cotton pellet induced granuloma by $57 \%$ compared with nontreated control and significant difference was recorded $(P<0.05)$. In addition, the combination of full dose of both agents produced the same quantitative effect; on the other hand, it reduced the cotton pellet induced granuloma by $49 \%$ compared with nontreated control group. These results may indicate that the extract has less anti-inflammatory effect than indomethacin. In addition, there was minor change with regard to the anti-inflammatory effect between half and full doses of both agents.

3.4. Antiulcerogenic Properties of C. penicillata and Gastritis Protection against Indomethacin. C. penicillata $400 \mathrm{mg} / \mathrm{kg}$ or indomethacin $10 \mathrm{mg} / \mathrm{kg}$ singly or in combination in half or full doses showed significant ulcerogenic potential evidenced in raising of ulcer score by $+50 \%,+250 \%,+150 \%$, and $+167 \%$ compared with normal control group, respectively (Table 4). The combination of $C$. penicillata with indomethacin reduced the ulcerogenic effect of indomethacin by $28 \%$ in case of half dose combination and by $24 \%$ in case of full dose combination compared with indomethacin. On the other hand, Figure 2 showed histopathological study of six groups that indicated the following: (a) normal control, (b) nontreated control "cotton pellet induced granuloma" that showed moderate degeneration of gastric glands, (c) treated group with indomethacin $(10 \mathrm{mg} / \mathrm{kg})$ that caused the wide spread necrosis of gastric glands, (d) treated group with $C$. penicillata that caused the mild degeneration with 
TABLE 1: The anti-inflammatory effect of single intragastric administration of different doses of C. penicillata on fresh egg albumen (0.5 mL/kg) induced paw oedema in adult male guinea pigs $(n=6)$ to find out the effective dose for further use in experimental studies.

\begin{tabular}{|c|c|c|c|c|c|c|c|}
\hline \multirow{2}{*}{ Groups } & \multirow{2}{*}{ Original paw volume } & \multicolumn{6}{|c|}{ Average volume of paw $(\mathrm{M} \pm \mathrm{SE})$ paw volume (cubic centimeter) } \\
\hline & & $30 \mathrm{~min}$ & $60 \mathrm{~min}$ & $90 \mathrm{~min}$ & $120 \mathrm{~min}$ & $150 \mathrm{~min}$ & $180 \mathrm{~min}$ \\
\hline \multirow{2}{*}{$\begin{array}{l}\text { Nontreated control } \\
\text { Difference of paw volume (cc) }\end{array}$} & \multirow{2}{*}{$3.15 \pm 0.10$} & $3.82 \pm 0.13^{*}$ & & & $4.0 \pm 0.16^{*}$ & $3.9 \pm 0.15^{*}$ & $3.57 \pm 0.14^{*}$ \\
\hline & & $0.7 \pm 0.04$ & $0.80 \pm 0.04$ & $1.2 \pm 0.03$ & $0.85 \pm 0.05$ & $0.75 \pm 0.04$ & $0.42 \pm 0.03$ \\
\hline \multirow{2}{*}{$\begin{array}{l}\text { C. penicillata ( } 200 \mathrm{mg} / \mathrm{kg}) \\
\text { Difference of paw volume (cc) }\end{array}$} & \multirow[t]{2}{*}{$3.08 \pm 0.07$} & $3.53 \pm 0.09^{*}$ & $3.78 \pm 0.09^{*}$ & $3.9 \pm 0.10^{*}$ & $3.75 \pm 0.10^{*}$ & $3.57 \pm 0.09^{*}$ & $3.47 \pm 0.09^{*}$ \\
\hline & & $0.45 \pm 0.03^{+}$ & $0.70 \pm 0.02^{+}$ & $0.82 \pm 0.03^{+}$ & $0.67 \pm 0.04^{+}$ & $0.49 \pm 0.05^{+}$ & $0.39 \pm 0.03^{+}$ \\
\hline \multirow{2}{*}{$\begin{array}{l}\text { C. penicillata ( } 400 \mathrm{mg} / \mathrm{kg} \text { ) } \\
\text { Difference of paw volume (cc) }\end{array}$} & \multirow[t]{2}{*}{$3.15 \pm 0.10$} & $3.57 \pm 0.11^{*}$ & $3.67 \pm 0.09^{*}$ & $3.65 \pm 0.10^{*}$ & $3.57 \pm 0.11^{*}$ & $3.47 \pm 0.11^{*}$ & $3.42 \pm 0.09^{*}$ \\
\hline & & $0.42 \pm 0.03^{+}$ & $0.52 \pm 0.04^{+}$ & $0.50 \pm 0.05^{+}$ & $0.42 \pm 0.03^{+}$ & $0.32 \pm 0.03^{+}$ & $0.27 \pm 0.03^{+}$ \\
\hline \multirow{2}{*}{$\begin{array}{l}\text { C. penicillata (600 mg/kg) } \\
\text { Difference of paw volume (cc) }\end{array}$} & \multirow[t]{2}{*}{$3.0 \pm 0.08$} & $3.40 \pm 0.06^{*}$ & $3.52 \pm 0.11^{*}$ & $3.53 \pm 0.11^{*}$ & $3.33 \pm 0.16^{*}$ & $3.32 \pm 0.11^{*}$ & $3.25 \pm 0.05^{*}$ \\
\hline & & $0.40 \pm 0.02^{+}$ & $0.52 \pm 0.03^{+}$ & $0.53 \pm 0.03^{+}$ & $0.33 \pm 0.02^{+}$ & $0.32 \pm 0.02^{+}$ & $0.25 \pm 0.02^{+}$ \\
\hline
\end{tabular}

${ }^{*}$ Significantly compared with original paw volume at $P<0.05$.

${ }^{+}$Significantly compared with nontreated control group at $P<0.05$.

cc: cubic centimeter.

TABLE 2: Effect of single dose intragastric administration of $10 \%$ ethanol extract of C. penicillata $(400 \mathrm{mg} / \mathrm{kg})$ versus indomethacin (10 mg/kg) on average $(\mathrm{M} \pm \mathrm{SE})$ volume (cubic centimeter) of fresh egg albumin $(0.5 \mathrm{~mL} / \mathrm{kg})$ induced paw oedema as a model of chronic inflammation $(n=6)$.

\begin{tabular}{|c|c|c|c|c|c|c|c|}
\hline \multirow{2}{*}{ Groups } & \multirow{2}{*}{ Original paw volume } & \multicolumn{6}{|c|}{ Average volume of paw $(\mathrm{M} \pm \mathrm{SE})$ paw volume (cubic centimeter) } \\
\hline & & $30 \mathrm{~min}$ & $60 \mathrm{~min}$ & $90 \mathrm{~min}$ & $120 \mathrm{~min}$ & $150 \mathrm{~min}$ & $180 \mathrm{~min}$ \\
\hline \multirow{2}{*}{$\begin{array}{l}\text { Nontreated control } \\
\text { Difference of paw volume (cc) }\end{array}$} & & $3.82 \pm 0.13^{*}$ & $3.95 \pm 0.13^{*}$ & $4.35 \pm 0.14^{*}$ & $4.0 \pm 0.16^{*}$ & $3.9 \pm 0.15^{*}$ & $3.57 \pm 0.14^{*}$ \\
\hline & & $0.7 \pm 0.04$ & $0.80 \pm 0.04$ & $1.2 \pm 0.03$ & $0.85 \pm 0.05$ & $0.75 \pm 0.04$ & $0.42 \pm 0.03$ \\
\hline \multirow{2}{*}{$\begin{array}{l}\text { Indomethacin }(10 \mathrm{mg} / \mathrm{kg}) \\
\text { Difference of paw volume (cc) }\end{array}$} & & $3.68 \pm 0.12^{*}$ & $3.78 \pm 0.11^{*}$ & $3.65 \pm 0.08^{*}$ & $3.48 \pm 0.04^{*}$ & $3.35 \pm 0.10$ & $3.30 \pm 0.1^{+}$ \\
\hline & & $0.50 \pm 0.05^{+}$ & $0.60 \pm 0.03^{+}$ & $0.47 \pm 0.03^{+}$ & $0.30 \pm 0.03^{+}$ & $0.17 \pm 0.02^{+}$ & $0.12 \pm 0.01^{+}$ \\
\hline \multirow{2}{*}{$\begin{array}{l}\text { C. penicillata ( } 400 \mathrm{mg} / \mathrm{kg}) \\
\text { Difference of paw volume (cc) }\end{array}$} & & $3.57 \pm 0.11^{*}$ & $3.67 \pm 0.09^{*}$ & $3.65 \pm 0.10^{*}$ & $3.57 \pm 0.11^{*}$ & $3.47 \pm 0.11^{*}$ & $3.42 \pm 0.09^{*}$ \\
\hline & & $0.42 \pm 0.03^{+}$ & $0.52 \pm 0.04^{+}$ & $0.50 \pm 0.05$ & $0.42 \pm 0.03^{+\epsilon}$ & $0.32 \pm 0.03^{+\epsilon}$ & $0.27 \pm 0.03^{+\epsilon}$ \\
\hline
\end{tabular}

${ }^{*}$ Significantly compared with original paw volume at $P<0.05$.

${ }^{+}$Significantly compared with nontreated control group at $P<0.05$.

${ }^{\epsilon}$ Significantly compared with indomethacin group at $P<0.05$.

TABLE 3: Anti-inflammatory effect of repeated intragastric administration of C. penicillata extract (400 mg/kg) and indomethacin (10 mg/kg) either singly or in combination on cotton pellet induced granuloma as a model of chronic inflammation $(n=6)$.

\begin{tabular}{lccccc}
\hline Groups & Nontreated control & $\begin{array}{c}\text { Indomethacin } \\
(10 \mathrm{mg} / \mathrm{kg})\end{array}$ & $\begin{array}{c}\text { C. penicillata } \\
(400 \mathrm{mg} / \mathrm{kg})\end{array}$ & Half dose combination & Full dose combination \\
\hline Dry granuloma $(\mathrm{mg})$ & $83.9 \pm 3.2$ & $22.9 \pm 2.8^{+}$ & $30.6 \pm 1.5^{+\epsilon}$ & $36 \pm 3.0^{+\epsilon}$ & $43 \pm 1.8^{+\epsilon}$ \\
\hline
\end{tabular}

Half dose combination: C. penicillata $(200 \mathrm{mg} / \mathrm{kg})$ with indomethacin $(5 \mathrm{mg} / \mathrm{kg})$; full dose combination: C. penicillata $(400 \mathrm{mg} / \mathrm{kg})$ with indomethacin $(10 \mathrm{mg} / \mathrm{kg})$.

${ }^{+}$Significantly compared with nontreated control group at $P<0.05$

${ }^{\epsilon}$ Significantly compared with indomethacin group at $P<0.0$.

TABLE 4: Effect of repeated intragastric administration of C. penicillata extract (400 mg/kg) and indomethacin (10 mg/kg) either singly or in combination in cotton pellet induced granuloma in adult male guinea pigs $(n=6)$ to find out the the ulcer index $(M \pm S E)$.

\begin{tabular}{lccccc}
\hline Groups & Normal control Nontreated control & $\begin{array}{c}\text { Indomethacin } \\
(10 \mathrm{mg} / \mathrm{kg})\end{array}$ & $\begin{array}{c}\text { C. penicillata } \\
(400 \mathrm{mg} / \mathrm{kg})\end{array}$ & Half dose combination Full dose combination \\
\hline Ulcer index & $1.2 \pm 0.10$ & $1.5 \pm 0.05^{*}$ & $4.2 \pm 0.31^{*+}$ & $1.8 \pm 0.11^{*+}$ & $3.0 \pm 0.27^{*+\epsilon}$ \\
\hline
\end{tabular}

${ }^{*}$ Significant compared with normal control values at $P<0.05$.

${ }^{+}$Significant compared with nontreated control group at $P<0.05$.

${ }^{\epsilon}$ Significant compared with indomethacin at $P<0.05$. 


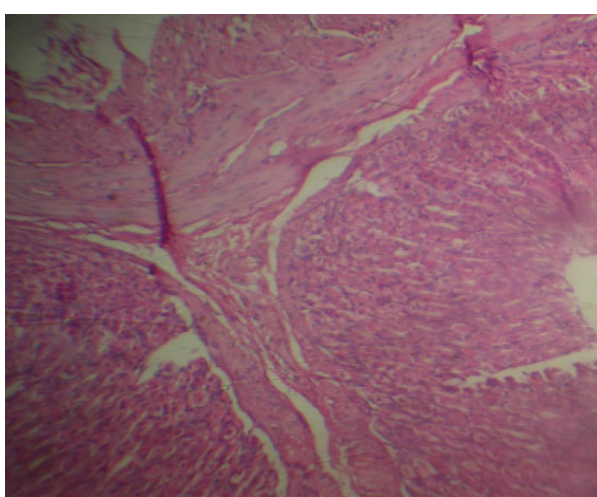

(a) Normal control

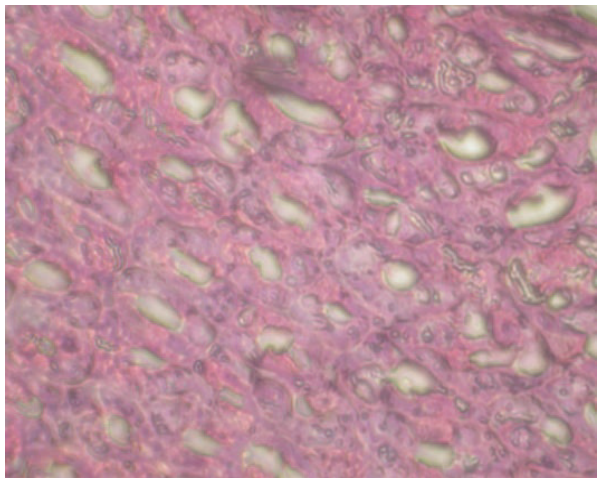

(c) Indomethacin caused wide spread necrosis of gastric glands

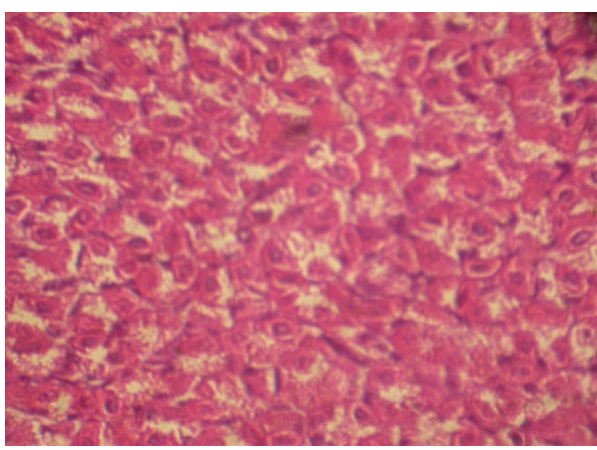

(e) C. penicillata $(200 \mathrm{mg} / \mathrm{kg})$ with indomethacin $(5 \mathrm{mg} / \mathrm{kg})$ caused moderate degeneration of gastric glandes

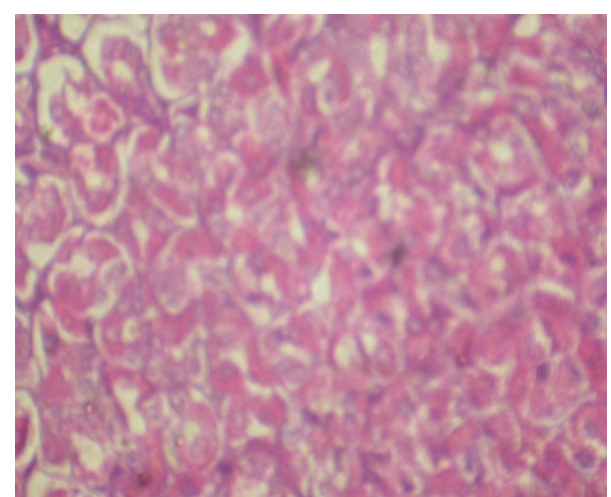

(b) Nontreated control cotton pellet induced granuloma showed moderate degeneration of gastric glands

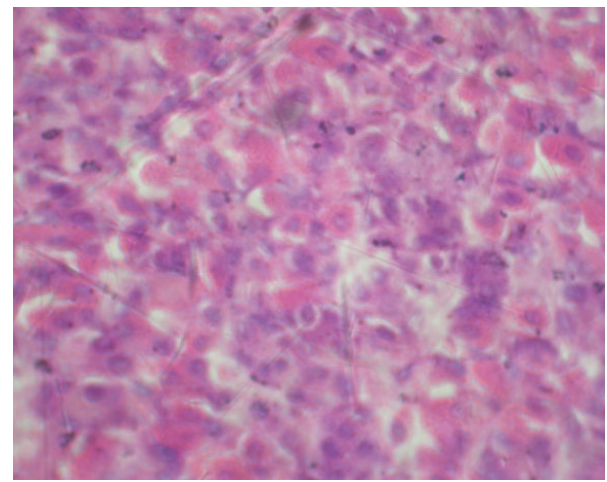

(d) C. penicillata mild degeneration with leukocytic infiltration

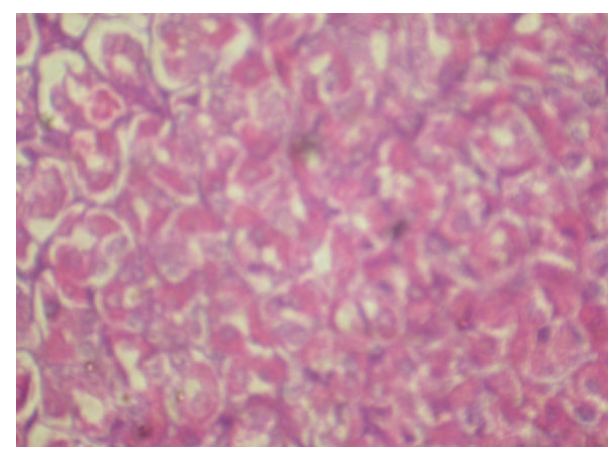

(f) C. penicillata $(400 \mathrm{mg} / \mathrm{kg})$ with indomethacin $(10 \mathrm{mg} / \mathrm{kg})$ caused necrosis of gastric mucosa, cell debris, and mild leukocytic infiltration

FIGURE 2: Histopathological study of normal control, nontreated control, indomethacin, C. penicillata, and half and full doses combination.

leukocytic infiltration, (e) treated group with C. penicillata $(200 \mathrm{mg} / \mathrm{kg})$ and indomethacin $(5 \mathrm{mg} / \mathrm{kg})$ as half combination form that caused moderate degeneration of gastric glands, and (f) treated group with C. penicillata $(400 \mathrm{mg} / \mathrm{kg}$ ) and indomethacin $(10 \mathrm{mg} / \mathrm{kg})$ as full combination form that caused necrosis of gastric mucosa, cell debris, and mild leukocytic infiltration.

\section{Discussion}

This study included testing of $10 \%$ ethanol extract of C. penicillata on two models of experimentally induced inflammation, namely, the fresh egg albumen induced paw oedema and production of granuloma by subcutaneous implantation of cotton pellet. The pathogenesis of both methods depends on the reaction of the body to foreign materials. In the former method $0.5 \mathrm{~mL} / \mathrm{kg}$ of fresh egg albumen was injected subplantarly. It acts as irritant foreign body which induced acute phase inflammatory reaction of short duration. It is characterized by the exudation of fluids and plasma proteins and emigration of leukocytes mainly neutrophil from the blood vessels and perivascular tissues to the site of foreign body implantation. The latter is mediated by interaction between complementary adhesion molecules 
present in leukocytes and endothelial surface. The expression of adhesion molecules is modulated by inflammatory agents. The volume of exudates is directly proportional to severity of acute inflammation [28]. On the other hand, the implantation of foreign body for relatively longer time as in case of cotton pellet implantation model of chronic inflammation promotes the formation of granuloma. It is a tumor like structure composed of macrophages, fibroblasts, and capillaries in varying amounts depending on the type of implanted substances. The weight of the granuloma is proportional to severity of inflammatory response [28].

The appropriate anti-inflammatory dose of extract was $400 \mathrm{mg} / \mathrm{kg}$ of $10 \%$ ethanol extract of the tested plant produced the optimum and maximal effect. The present work revealed that the extract produced equipotent anti-inflammatory effect to an intragastric dose of indomethacin amounted to $10 \mathrm{mg} / \mathrm{kg}$ for the first 90 minutes and then indomethacin was superior to the tested extract in the last 90 minutes of experimental period. This may imply that the tested extract had shorter duration of action than indomethacin that acts by inhibition of inflammatory pathway of inflammatory prostaglandin synthesis by inhibition of cyclooxygenase- 2 . Prostaglandins E1, E2, and D series are potent inflammatory mediators. They mediate acute inflammatory response through increasing capillary permeability and endothelial dysfunction [29].

The anti-inflammatory effect of extract is in conformation with the previous reports for other species of this plant. Ramesh et al. showed that either orally administrated extract of C. arabica in a dose of $200-400 \mathrm{mg} / \mathrm{kg}$ or topical $5 \%$ gel reduced carrageenan induced paw oedema [7]. Moreover, acute oral dose of the previously mentioned plant extract produced significant antinociceptive effect on various models of pain, namely, tail flick test, abdominal constriction test, and hot plate test. It is hard to define the mechanism of such effect and it needs a detailed phytochemical study to identify the active constituents of extract. Nevertheless, it may be assumed that the high flavonoids, sterols, and triterpenes of extract are the active ingredients responsible for the antiinflammatory effect. In 1999, Qiu et al. isolated a common flavonoid glycoside, luteolin-4-O-neohesperidoside in most C. genera [30]. Ramesh et al. in 1998 isolated the above mentioned flavonoid from C. attenuate. A dose of $3-4 \mathrm{mg} / \mathrm{kg}$ was used as potent anti-inflammatory comparing to a $50 \mathrm{mg} / \mathrm{kg}$ of Ibuprofen. Higher doses $(100 \mathrm{mg} / \mathrm{kg})$ exerted antinociceptive effects. It may exert the anti-inflammatory effect by acting as free radical scavenger [31]. Ansari et al., 2005, showed a potent positive correlation between the antioxidant effect and the biological effects of Caralluma species and oxidative free radicals are highly reactive substances produced by granulocytes in response to engulfing of foreign materials [32].

Compared with $10 \mathrm{mg} / \mathrm{kg}$ intragastric indomethacin, the tested extract produced less potent anti-inflammatory effect. Indomethacin- $C$. penicillata combination antagonized each of them regarding the anti-inflammatory effect. This may be explained by pharmacokinetic antagonism as a result of the combined agents with regard to their gastrointestinal absorption. Indomethacin is weakly acidic drug related to indole acetic acid group [33]. The weakly acidic drugs like indomethacin are less ionized and highly absorbable in acidic media. Coadministration of $C$. penicillata and indomethacin may inhibit gastrointestinal absorption of indomethacin by reducing gastrointestinal acidity through its high mineral basic substances as well as simple volume dilution effect [34]. Concerning the effect of the tested agents on gastric mucosa, either indomethacin or C. penicillata significantly raised ulcer index compared with normal control and nontreated groups. This may indicate that the tested agents have a marked ulcerogenic potential. This may be attributed to the effect of indomethacin in decreasing synthesis of protective prostaglandins in gastric mucosa. The latter exerts cytoprotective effect by increasing mucous secretion and vasodilatation of mucous blood vessels. It is worth mentioning that indomethacin inhibits cyclooxygenase-I responsible for synthesis of physiological prostaglandins compared to cyclooxygenase-II that is responsible for synthesis of inflammatory prostaglandin [35]. On the other hand, the ulcerogenic effect of $C$. penicillata was hard to be explained from the available data and combination of $C$. penicillata in full dose significantly reduced the ulcerogenic effect of indomethacin. This may be attributed to formation of inactive complex of the two agents in gastric mucosa. The coadministration of both agents in half the therapeutic dose significantly reduced the ulcerogenic potential and anti-inflammatory effect compared with indomethacin alone but it is more toxic and as effective compared with $C$. penicillata alone. The above mentioned combination is as effective as and less toxic than combining the full therapeutic dose of both agents. These data may imply that the modest anti-inflammatory effect and the least ulcerogenic effect can be obtained by combining half the therapeutic dose of both indomethacin and $C$. penicillata. This is in conformation with the work of Al-Harbi et al. who showed that C. tuberculata at doses of 250, 500 , and $1000 \mathrm{mg} / \mathrm{kg}$ provided dose-dependent protection against the damage caused by $80 \%$ ethanol, $0.2 \mathrm{M} \mathrm{NaOH}$, hypertonic saline, and indomethacin and it can be assumed that the $C$. species has both ulcerogenic and cytoprotective effects; the former effects predominated when the drug was taken alone. This may be due to sterols content. On the contrary, the cytoprotective effect predominated when the plant is combined with ulcerogenic agents like indomethacin. This may be due to increase of production of mucous and prostaglandin, free radical scavenging, and sulfhydryl compound spearing effects [3]. Finally, the ulcerogenic potential of tested agents observed in this work was well correlated with microscopic study of gastric mucosa. The latter revealed that cotton pellet implantation caused mild degeneration changes in gastric glands. Probably due to immune mediated mechanism triggered by foreign implantation, doses of $C$. penicillata produced mild degeneration with leukocytic infiltration mucosa. Indomethacin alone produced wide spread necrosis of gastric mucosa with accumulation of cell debris in gastric glands. These changes persisted but in milder form when indomethacin was admitted in combination with $C$. penicillata. This result indicated partial activity of extract to protect the mucosa from side effect of indomethacin. 
In conclusion, the extract of $C$. penicillata but hadantiinflammatory effect against acute and chronic models of inflammation. A single dose of $400 \mathrm{mg} / \mathrm{kg}$ of the extract was equipotent for efficient indomethacin but shorter action than it. The repeated of dose extract was less effective as antiinflammatory and ulcerogenic potential than indomethacin. In brief, this study has shown that C. penicillata possesses anti-inflammatory and antiulcerogenic properties, thus confirming the claim by traditional medical practitioners. Further studies are necessary in order to determine the active ingredients in the plant and to evaluate the specific action mechanism of this plant.

\section{Conflict of Interests}

The authors declare that there is no conflict of interests regarding the publication of this paper.

\section{Acknowledgments}

The authors would like to thank the Professor Nasser Zawyia, Dean of Graduate Study, College of Pharmacy, Rhode Island University, and the director and staff of the Tihama Foundation for Drug Studies and Research (TFDSR), Hodeidah, Yemen, for their fruitful assistance.

\section{References}

[1] A. Bader, A. Braca, N. de Tommasi, and I. Morelli, "Further constituents from Caralluma negevensis," Phytochemistry, vol. 62, no. 8, pp. 1277-1281, 2003.

[2] S. Venkatesh, G. D. Reddy, B. M. Reddy, M. Ramesh, and A. V. N. A. Rao, "Antihyperglycemic activity of Caralluma attenuata," Fitoterapia, vol. 74, no. 3, pp. 274-279, 2003.

[3] M. D. Al-Harbi, S. Qureshi, M. Raza, M. M. Ahmed, M. Afzal, and A. H. Shah, "Evaluation of Caralluma tuberculafa pretreatment for the protection of rat gastric mucosa against toxic damage," Toxicology and Applied Pharmacology, vol. 128, no. 1, pp. 1-8, 1994.

[4] D. Deepak, A. Khare, and M. P. Khare, "Plant pregnanes," Phytochemistry, vol. 28, no. 12, pp. 3255-3263, 1989.

[5] D. Deepak, S. Srivastav, and A. Khare, "Pregnane glycosides," Progress in the Chemistry of Organic Natural Products, vol. 71, pp. 169-325, 1997.

[6] M. N. M. Zakaria, M. W. Islam, R. Radhakrishnan et al., "Antinociceptive and anti-inflammatory properties of Caralluma arabica," Journal of Ethnopharmacology, vol. 76, no. 2, pp. 155158, 2001.

[7] M. Ramesh, Y. N. Rao, M. R. Kumar et al., "Flavone glycoside from three Caralluma species," Biochemical Systematics and Ecology, vol. 27, no. 1, pp. 85-86, 1999.

[8] M. A. Al-Yahya, M. Tariq, T. I. Khalifa, and I. Ashraf, "Toxicity studies on Caralluma penicillata-a poisonous plant from Saudi Arabia," Toxicon, vol. 21, no. 3, pp. 9-12, 1983.

[9] S. Venkatesh, G. D. Reddy, B. M. Reddy, M. Ramesh, and A. V. N. A. Rao, "Antihyperglycemic activity of Caralluma attenuata," Fitoterapia, vol. 74, no. 3, pp. 274-279, 2003.

[10] L.-J. Lin, L.-Z. Lin, R. R. Gil et al., "Pregnane glycosides from Caralluma Umbellata," Phytochemistry, vol. 35, no. 6, pp. 15491553, 1994.
[11] A. Braca, A. Bader, I. Morelli et al., "New pregnane glycosides from Caralluma negevensis," Tetrahedron, vol. 58, no. 29, pp. 5837-5848, 2002.

[12] M. M. Ahmed, S. Qureshi, A. M. Al-Bekairi, A. H. Shah, R. M. Rao, and N. S. Qazi, "Anti-inflammatory activity of Caralluma tuberculata alcoholic extract," Fitoterapia, vol. 64, no. 4, pp. 357360, 1993.

[13] E. Abdel-Sattar, M. A.-A. Al-Yahya, N. Nakamura, and M. Hattori, "Penicillosides A-C, C-15 oxypregnane glycosides from Caralluma penicillata," Phytochemistry, vol. 57, no. 8, pp. 12131217, 2001.

[14] E. Abdel-Sattar, M. R. Meselhy, and M. A. A. Al-Yahya, "New oxypregnane glycosides from Caralluma penicillata," Planta Medica, vol. 68, no. 5, pp. 430-434, 2002.

[15] A. Panthong, D. Kanjanapothi, Y. Thitiponpunt, T. Taesotikul, and D. Arbain, "Anti-inflammatory activity of the alkaloid bukittinggine from Sapium baccatum," Planta Medica, vol. 64, no. 6, pp. 530-535, 1998.

[16] C. A. Winter, E. A. Risely, and G. W. Nuss, "Carrageenininduced edema in hind paw of the rat as an assay for antiiflammatory drugs," Proceedings of the Society for Experimental Biology and Medicine, vol. 111, pp. 544-547, 1962.

[17] P. A. Akah and A. I. Nwambie, "Evaluation of Nigerian traditional medicines: 1. Plants used for rheumatic (inflammatory) disorders," Journal of Ethnopharmacology, vol. 42, no. 3, pp. 179$182,1994$.

[18] D. Chu and B. A. Kovacs, "Anti-inflammatory activity in oak gall extracts," Archives Internationales de Pharmacodynamie et de Therapie, vol. 230, no. 1, pp. 166-176, 1977.

[19] F. T. Fischbach and B. Marshall, A Manual of Laboratory Diagnostic Tests, J. B. Lippincott, Philadelphia, Pa, USA, 8th edition, 2008.

[20] R. Meier, W. Schuler, and P. Desaulles, “Zur Frage des Mechanismus der Hemmung des Bindegewebswachstums durch Cortisone," Experientia, vol. 6, no. 12, pp. 469-471, 1950.

[21] U. K. Sheth, N. K. Dadkar, and U. K. Kama, Selected Topics in Experimental Pharmacology, The Kothari Book Depot, Bombay, India, 1st edition, 1972.

[22] A. D. Sedgwick and D. A. Willoughby, "Animal models for testing drugs on inflammatory and hypersensitivity reactions," in Textbook of Immunopharmacology, Blackwell Scientific Publication, London, UK, 2nd edition, 1989.

[23] C. A. Hiruma-Lima, R. C. Spadari-Bratfisch, D. M. GrassiKassisse, and A. R. M. Souza Brito, "Antiulcerogenic mechanisms of dehydrocrotonin, a diterpene lactone obtained from Croton cajucara," Planta Medica, vol. 65, no. 4, pp. 325-330, 1999.

[24] K. F. Swingle and F. E. Shideman, "Phases of the inflammatory response to subcutaneous implantation of a cotton pellet and their modification by certain anti-inflammatory agents," Journal of Pharmacology and Experimental Therapeutics, vol. 183, no. 1, pp. 226-234, 1972.

[25] S. Maity, T. Chaudhuri, J. R. Vedasiromoni, and D. K. Ganguly, "Cytoprotection mediated antiulcer effect of tea root extract," Indian Journal of Pharmacology, vol. 35, no. 4, pp. 213-219, 2003.

[26] R. A. B. Drury, E. A. Wallington, and R. Cameron, Carleton's Histological Techniques, Oxford University Press, New York, NY, USA, 4th edition, 1967.

[27] V. Kumar, K. Abul Abbas, and C. Jon Aster, Robbins Basic Pathology, Saunders, Philadelphia, Pa, USA, 8th edition, 2008. 
[28] J. M. Anderson, "Biological responses to materials," Annual Review of Materials Research, vol. 31, pp. 81-110, 2001.

[29] P. Davies, P. J. Bailey, M. M. Goldenberg, and A. W. FordHutchinson, "The role of arachidonic acid oxygenation products in pain and inflammation," Annual Review of Immunology, vol. 2, pp. 335-357, 1984.

[30] S.-X. Qiu, G. A. Cordell, B. R. Kumar et al., "Bisdesmosidic pregnane glycosides from Caralluma lasiantha," Phytochemistry, vol. 50, no. 3, pp. 485-491, 1999.

[31] M. Ramesh, Y. Nageshwar Rao, A. V. N. Appa Rao et al., "Antinociceptive and anti-inflammatory activity of a flavonoid isolated from Caralluma attenuata," Journal of Ethnopharmacology, vol. 62, no. 1, pp. 63-66, 1998.

[32] N. M. Ansari, L. Houlihan, B. Hussain, and A. Pieroni, "Antioxidant activity of five vegetables traditionally consumed by SouthAsian migrants in Bradford, Yorkshire, UK," Phytotherapy Research, vol. 19, no. 10, pp. 907-911, 2005.

[33] D. E. Furst and T. Munster, Non-Steroidal Anti-Inflammatory Drugs, Basic and Clinical Pharmacology, Lange Medical Book/ McGraw Hill Medical Publishing Division, 8th edition, 2001.

[34] N. H. G. Holford and L. Z. Benet, Pharmacokinetics and Pharmacodynamics: Dose Selection and the Time Course of Drug Action, Basic and Clinical Pharmacology, Appleton-Lange, 2001.

[35] M. Moulin and A. Coquerel, Pharmacologie, Connaissance et Pratique III MASSON, 2nd edition, 2000. 

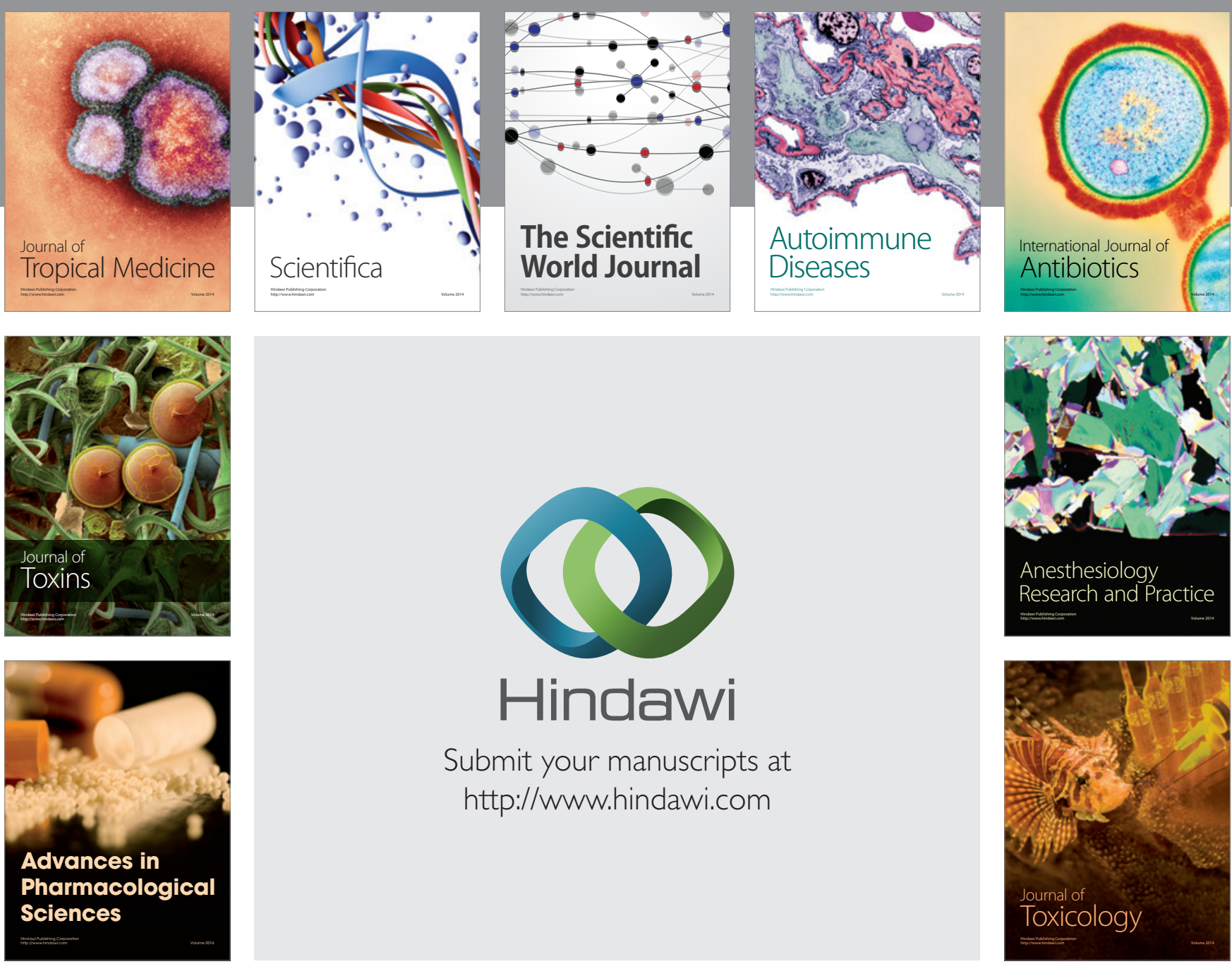

\section{Hindawi}

Submit your manuscripts at

http://www.hindawi.com
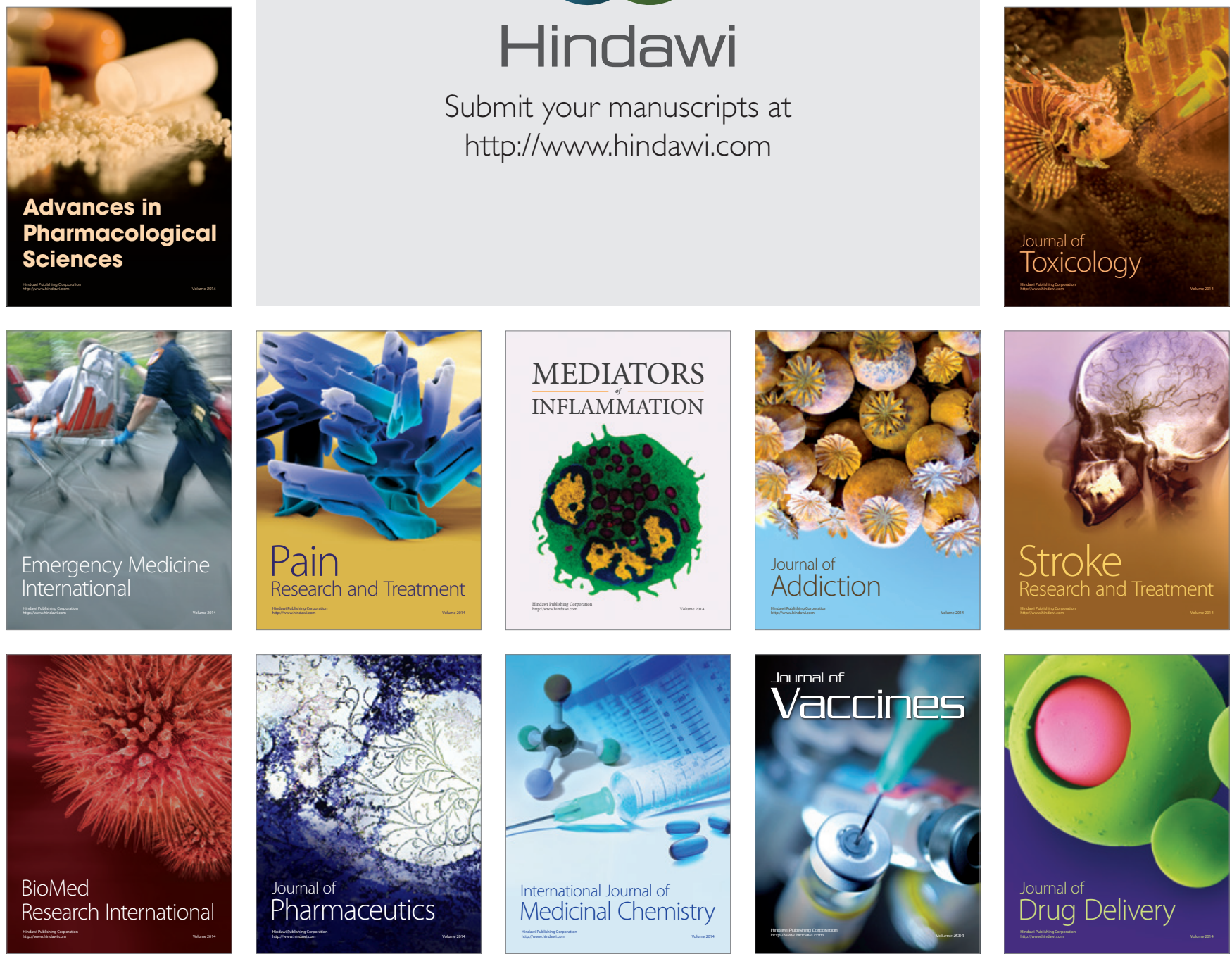